\title{
O Tratado do Impulso e da Faculdade Impulsiva de Alexandre de Afrodísia e sua versão em Miguel de Éfeso
}

Marco Zingano (USP)

After a presentation of Michael's version of a part of Alexander's De anima called On Impulse, follow Portuguese translations of Alexander's De anima 73,14 - 80, 15, Michael of Ephesus' commentary on Aristotle's De motu 114, 22 - 116, 14, and Alexander's Mantissa 105, 26 - 106, 17, accompanied by very brief notes.

Em seu comentário ao De motu animalium, Miguel de Éfeso, ao completar o comentário do capítulo 6, faz referência a um tratado por ele denominado

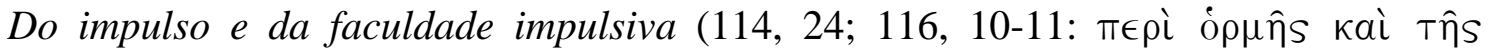

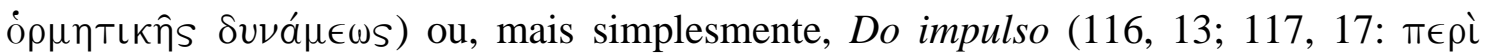
$\dot{\rho} \rho \mu \hat{\eta} s)$. Miguel alega que todo aquele que quer compreender como a alma usa os órgãos para dar movimento ao corpo sem que ela própria se mova deve ler este tratado, pois ele fornece "toda a concepção de Aristóteles” a este respeito; por esta razão, Miguel passa a relatar neste seu comentário ao De motu algumas das lições deste tratado. A passagem ocupa as linhas 114, 27 - 116, 11 de seu comentário ao De motu.

A expressão que Miguel usa para referir-se a este tratado não é de todo

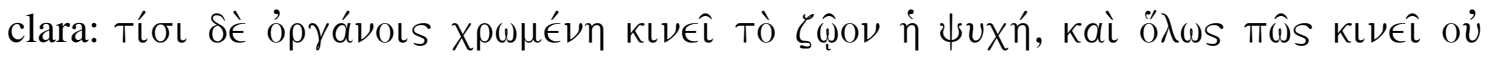

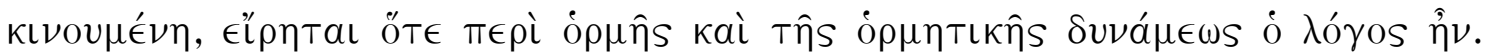

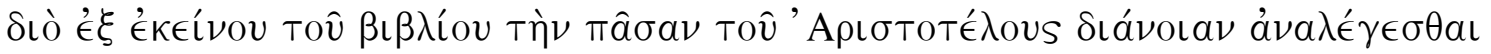

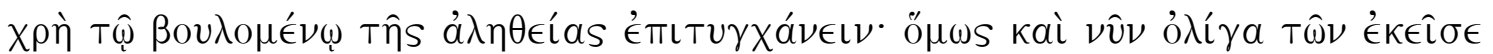

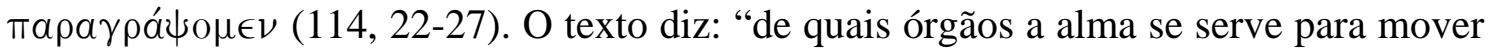
o animal e, em geral, como ela move o animal sem ser movida, foi explicado quando do tratado do impulso e da faculdade impulsiva. Por isso quem quiser obter a verdade deve ler a inteira concepção de Aristóteles deste livro; agora, contudo, vamos transcrever um pouco do que está escrito lá.”. Ele claramente nos diz que passa a examinar as funções 
Journal of Ancient Philosophy Vol. II 2008 Issue 2

comuns entre alma e órgãos a respeito do movimento - o que, espera-se, foi em boa parte tratado no De motu animalium. Não fica claro, porém, de quem é a autoria do tratado Do impulso. Miguel pode estar querendo dizer que "agora, contudo, vamos escrever um pouco do que escrevemos lá”, subentendendo que o tratado é de sua autoria, ou que “agora, contudo, vamos transcrever um pouco do que está escrito lá”, sem subentender, longe disso, que seja o autor do tratado. M. Hayduck, o editor do texto para a $C A G$, o toma como sendo um tratado do próprio Miguel, opinião que parece ter perdurado até recentemente, quando, em 1968, P.L. Donini publicou um artigo mostrando que se tratava claramente de excertos copiados de uma parte do De anima de

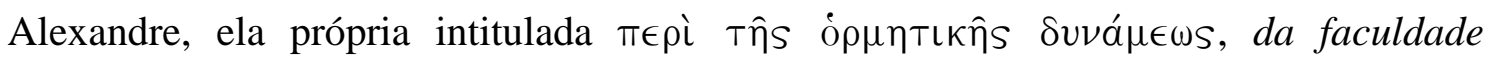
impulsiva (De anima 73, 14 - 80, 15). ${ }^{1}$ Pode-se sustentar que a frase "quando do tratado do impulso e da faculdade impulsiva” nos força a atribuir a autoria do tratado ao próprio Miguel. Este sentimento é reforçado pelo fato de Miguel mencionar por duas

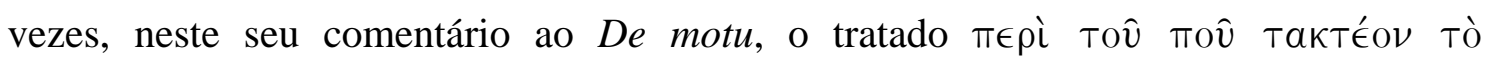

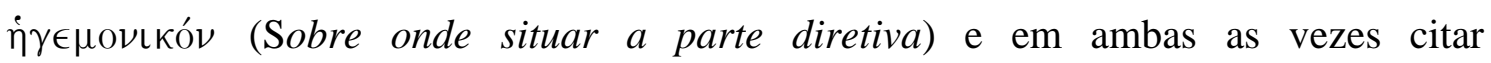
expressamente seu autor, Alexandre de Afrodísia (trata-se também, com efeito, de uma parte do De anima de Alexandre, a saber, as páginas finais 94.7 - 100.17, que iniciam justamente com a questão “onde se localiza a parte diretiva da alma”). Neste caso, supondo que não se trata de simples usurpação de autoria, deveríamos supor que Miguel escreveu um certo tratado Do impulso, maior do que a presente versão, mas menor do que o texto de Alexandre, que não possuímos mais - o que parece ser pouco natural. Ou bem se admite uma simples usurpação de autoria - mas Miguel cita em outros momentos Alexandre e não parece esconder o fato que copia seguidamente passagens extensas de Alexandre. Parece então mais simples entender aqui que Miguel está anunciando que vai transcrever partes da obra de um outro autor, que ele não menciona por nome, mas que hoje sabemos ser com exatidão Alexandre de Afrodísia. Quanto à diferença de procedimento relativamente à cópia deste tratado e a do tratado da localização da parte diretiva (pois do primeiro não cita o autor, enquanto o menciona

\footnotetext{
${ }^{1}$ P.L. Donini, Il De anima di Alessandro di Afrodisia e Michele Efesio, Rivista de Filologia e di Istruzione Classica XCVI / 3 1968, pp. 316-323. A. Preus mantém a tese de uma reivindicação de autoria por parte de Miguel quanto a este tratado: Aristotle and Michael of Ephesus On the movement and progression of animals, Olms 1981, p. 17 n. 38.
} 
Journal of Ancient Philosophy Vol. II 2008 Issue 2

duas vezes o do segundo), ela pode ser explicada pelo fato de Miguel glosar ou fazer somente paráfrases do tratado Sobre onde situar a parte diretiva, ao passo que, relativamente ao tratado Do impulso, Miguel copia com uma literalidade impressionante um bom número de passagens: o primeiro requeria assim certificado de origem, mas não o último, cuja evidência de autoria dispensava qualquer menção suplementar.

As passagens com transcrição são as seguintes, no tocante unicamente ao Do impulso e da faculdade impulsiva: ${ }^{2}$

1. Alexandre $73,17-74,1$

2. Alexandre $76,6-9$

3. Alexandre 76, $9-77,17$

4. Alexandre $78,24-79,4$

5. Alexandre $79,16-17$

6. Alexandre $79,17-20$
Miguel 103, 2-11

Miguel 114, 27-29

Miguel 114, 29 - 115, 25

Miguel 115, 25 - 116, 1

Miguel 116, 2-3

Miguel 116, 3-10

Forneço a seguir, primeiramente, a tradução do original de Alexandre e, em seguida, a transcrição de Miguel de Éfeso; ao final, incluo uma passagem referente ao mesmo ponto no que é como que um apêndice ao De anima de Alexandre, conhecido pelo título de Mantissa. Um primeiro interesse diz respeito, obviamente, ao procedimento de “citação” de que se serve Miguel. Pertencente ao círculo de Anna Comnena, Miguel parece ter feito extensivo recurso à transcrição dos comentários de Alexandre. Ao se comparar os textos, pode-se ter uma idéia de seu comportamento literário, e isso em duas direções. Primeiramente naquilo que podemos imaginar com muita plausibilidade ter sido transcrito por ele dos originais de Alexandre que hoje não nos são mais disponíveis. Um caso particularmente importante é o comentário de Alexandre da Metafísica a partir do livro VII, atribuído a um outro escritor; se o “pseudo-Alexandre” não é outro senão o próprio Miguel, podemos esperar encontrar aí passagens razoavelmente extensas copiadas verbatim, assim como vemos ocorrer no presente tratado.

\footnotetext{
${ }^{2}$ A lista está em Donini, op. cit., p. 317; a estas transcrições devem ser acrescentadas outras passagens do De anima de Alexandre que Miguel menciona em outros comentários seus, que Donini igualmente lista.
} 
Journal of Ancient Philosophy Vol. II 2008 Issue 2

Em segundo lugar, porém, inversamente, pois podemos aperfeiçoar as lições dos manuscritos de Alexandre com base na cópia que produziu Miguel. Um caso exemplar já tinha sido muito bem exposto por Donini. No De anima de Alexandre, lê-se que,

“assim como na parte crítica uma é diretiva e a outra é subordinada, assim também, na parte prática, uma é diretiva, a qual denominamos de impulsiva e desiderativa, a outra é algo que está nos tendões/nervos. Há, pois, também neles uma faculdade, com base na qual o corpo subordina-se às atividades com base em um impulso". (76, 14-17)

O editor do texto, Ivo Bruns, desconfiou que algum termo tivesse desaparecido após "tendões/nervos” e sugeriu, no aparato crítico, algo como

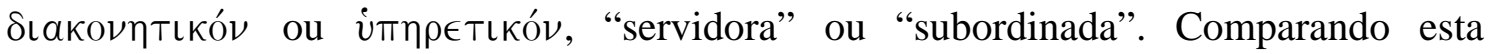
passagem com a versão de Miguel, há mais do que um termo a ser acrescentado:

“assim como na parte crítica uma é diretiva e a outra é subordinada, assim também, na parte prática, uma é diretiva, a qual denominamos de impulsiva e desiderativa, a outra é algo que está nos tendões/nervos a título de subordinada, que denominamos também de “neurospastikon”. Há, pois, também neles uma faculdade, com base na qual o corpo subordina-se às atividades por impulso" $(115,3-7){ }^{3}$

O texto de Miguel nos permite assim reconstituir com maior segurança a passagem em Alexandre. Uma segunda correção, também proposta por Donini, se localiza entre o aporte filológico e o filosófico, mas parece menos segura. Em certo momento de seu De anima, ao falar das várias espécies da parte impulsiva, Alexandre escreve o seguinte:

Foi dito então que as faculdades da parte impulsiva e desiderativa são várias e que diferem umas das outras quanto ao tempo, quanto aos objetos e quanto aos sujeitos a que pertencem. Havia sido dito antes que também há diferença entre as faculdades cognitivas e críticas. (76, 6-9)

A versão de Miguel omite uma parte do texto:

$<$ É> dito primeiramente que as faculdades da parte desiderativa e impulsiva são várias e, por último, que também há diferença entre as faculdades cognitivas e críticas. (114, 27-29)

\footnotetext{
${ }^{3}$ Ver Donini, Il de anima, p. 318, que observa que o termo $v \in v \rho \circ \sigma \pi a \sigma \tau \iota \kappa o ́ v$ se encontra na passagem paralela a esta do Mantissa, o que garante sua estirpe alexandrina. O termo designa a fiação das marionetes ou, o que parece ser mais próprio aqui, o que é capaz de contrair e relaxar, puxar e largar por mecanismos similares (como músculos, tendões e nervos).
} 
Journal of Ancient Philosophy Vol. II 2008 Issue 2

A razão, como sugeriu Donini, pode bem ser filosófica. As várias faculdades da parte impulsiva são a ira, o apetite, o querer e as respectivas faculdades de repulsa. Ora, não parece haver sentido em falar de diferença no tempo entre a ira, o apetite ou o querer, como se houvesse uma sucessão entre eles: primeiro o apetite, ou a ira, depois o outro, ou primeiro um impulso não-racional, seja a ira ou o apetite, e depois o racional. O silêncio de Miguel pode estar aqui traduzindo sua surpresa de encontrar uma tal tese em Alexandre. Tenho a impressão, porém, que Alexandre não estava dizendo exatamente isso, mas sim que foi mostrado que (i) há várias espécies da parte impulsiva e desiderativa e que (ii) estas várias espécies, tomadas conjuntamente, isto é, como a inteira parte impulsiva, diferem das outras partes, como a sensitiva, pelo tempo e pelo sujeito a que pertencem. Isso, aliás, se coaduna melhor com o texto de Alexandre, pois foi justamente o que fez nas linhas anteriores. ${ }^{4} \mathrm{O}$ problema aqui parece ser antes que é preciso subentender como sujeito de (ii) não as espécies da parte impulsiva separatim, mas o seu conjunto ou, em outros termos, a própria parte impulsiva, e então referir o $a \lambda \lambda \eta \dot{\eta} \lambda \omega \nu$ não às espécies, mas às outras partes, como a sensitiva, que, como foi mostrado antes, é anterior cronologicamente à impulsiva. Miguel não parece estar corrigindo Alexandre, mas ficou hesitante diante de uma ambigüidade sintática e preferiu a glosa.

Um segundo interesse, e talvez maior, consiste no exame do tratado mesmo de Alexandre sobre a parte impulsiva. Sobre isso, parece conveniente distinguir entre o que este tratado introduz na análise do movimento em geral, em uma perspectiva típica de um tratado da alma, e o que ele recupera do De motu animalium em particular, quando pretende, como alega Miguel, explicar como a alma se serve dos órgãos para mover o animal sem ela própria se mover, examinando-a do ponto de vista do que é comum ao corpo e à faculdade. Vou começar pela primeira e terminar pela segunda. $\mathrm{O}$ primeiro elemento a observar é, então, a ordem que Alexandre deu ao seu tratado De anima. Nas primeiras páginas (1-26), ele concentra sua atenção no problema da

\footnotetext{
${ }^{4}$ Pode-se, é claro, tentar explicar o texto de Alexandre e encontrar uma ordem cronológica entre os tipos de desejo: como a ira e o apetite são comuns aos animais e ocorrem de início na criança, que, esta última, desenvolve somente com o tempo os conceitos necessários para formular os desejos de tipo racional, isto é, o querer, então se poderia ver aqui uma perspectiva temporal entre eles. No entanto, uma tal consideração não figura no que foi dito anteriormente, mas somente a da ordem temporal relativamente à parte impulsiva, sensitiva e nutritiva.
} 
Journal of Ancient Philosophy Vol. II 2008 Issue 2

definição e da natureza da alma em sua ligação com o corpo; de 27 a 31, 6, ele mostra que há mais de uma espécie da alma, mas que esse número é limitado, a saber, há três espécies: a alma nutritiva, a sensitiva e a racional. Feito isso, Alexandre examina a alma nutritiva de 31, 7 a 38, 11. Após este estudo, ele se volta à alma sensitiva, a partir de 38, 12, da qual dá uma definição geral em 38, 21 - 39, 2. Obtida a definição geral, Alexandre examina primeiramente a visão $(42,4$ - 46, 19), depois a audição $(46,20$ $51,4)$, o olfato $(51,5-53,1)$, o gosto $(53,2-55,14)$ e o tato $(55,15-59,24)$, para, depois de um resumo dos resultados obtidos (60, 1-14), examinar o sentido comum (60, 14 - 66, 8) e a imaginação $(66,9$ - 73, 13). Com ligeiras alterações, o plano da obra segue de perto o que está traçado no livro II e no início do livro III do De anima de Aristóteles. É agora, em 73, 14 - 80, 15, que Alexandre examina a faculdade impulsiva; após este exame, ele passa a estudar o pensamento (80, 16 - 92, 11), que é seguido de uma parte final na qual defende o coração como sede da alma, inclusive para o pensamento (92, 12 - 100, 17).

O tratado Do impulso e da faculdade impulsiva apresenta assim, na ordem do estudo de Alexandre, uma divergência com a ordem estabelecida no De anima de Aristóteles, pois, neste último, o estudo da faculdade de pensar (III 4 - 8) segue imediatamente a análise da sensação (III 3) e é seguido, por sua vez, pelo exame da faculdade motora (III 9 - 11). Ora, para Alexandre, a alma dos animais deve ser dividida em uma parte crítica e outra prática; na parte crítica está a sensação, mas também a razão, e poderíamos esperar que esta última fosse tratada em seqüência àquela para dar, deste modo, um tratamento completo à parte crítica. Porém, como a razão é exclusiva aos homens e os animais se movem localmente pela faculdade impulsiva, Alexandre decide primeiro tratar desta para somente depois analisar a função discriminativa racional, própria aos homens unicamente. Procedendo desta forma Alexandre também propõe uma ordem em que a dignidade do objeto é ressaltada pela sua posição final: o último a ser tratado é o elemento racional e este elemento é o que maior dignidade possui. ${ }^{5}$

\footnotetext{
${ }^{5}$ No entanto, em De anima II 3 414a31-32 de Aristóteles, a ordem proposta é (a) faculdade nutritiva, (b) faculdade sensitiva, (c) faculdade desiderativa, (d) faculdade de movimento local e (e) faculdade de reflexão ; a posição posterior e, simultaneamente, de maior nobreza do intelecto em relação à função motora é novamente acentuada algumas linhas depois, em 414b16-19. Isso
} 
Journal of Ancient Philosophy Vol. II 2008 Issue 2

Por outro lado, a análise está fortemente enquadrada pela teoria estóica da ação, não somente em sua terminologia, mas também em sua ordem: dada uma apreensão, segue-se o assentimento dado ou não ao que é percebido e, em função disso, o impulso pela busca ou pela fuga, o que se terminará na ação (na ordem que o próprio

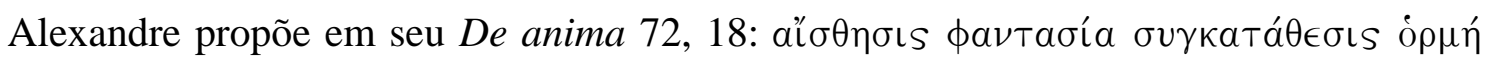
$\pi \rho \hat{a} \xi ı s)$. Esta ordem estóica produz um resultado notável, a saber, que o movimento dos

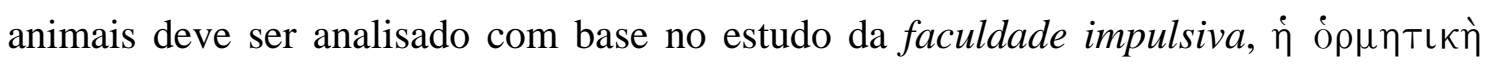

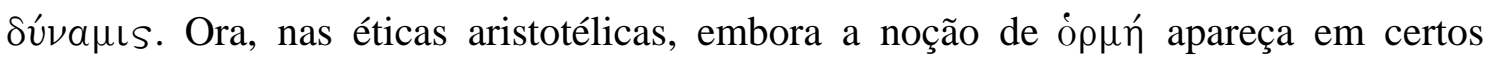
contextos (em ordem decrescente quanto ao número: Magna Moralia, Ethica Eudemia e Ethica Nicomachea), Aristóteles não examina a ação humana sob o comando da noção de impulso que se segue ao assentimento, mas, ao contrário, ele toma como princípio final da escolha deliberada o desejo, isto é, a representação de um objeto como desejável (o que ocuparia a posição do impulso), a escolha deliberada sendo ela própria princípio eficiente da ação (EN VI 2 1139a31-33). Não se trata, a meu ver, de uma questão meramente de ordem ou, ainda, de terminologia. De fato, parece haver um problema maior aqui. Na medida em que o movimento e a ação são pensados à luz do impulso que dá seguimento ao assentimento dado a uma impressão, é certamente possível encontrar um espaço para a deliberação - justamente pelo fato do assentimento racional não ser mecânico e poder criar uma distância quanto àquilo que nos é dado pela impressão -; no entanto, não é mais possível reivindicar ao espaço deliberativo uma certa interpretação da ação tal que aquilo que o sujeito pode fazer em um dado momento para obter um determinado objeto de seu desejo, ele pode deixar de o fazer neste mesmo momento.

A reflexão deliberativa, em Aristóteles, constitui o cerne do uso prático da razão (com efeito, o prudente, a figura moral aristotélica por excelência, quem paradigmaticamente age bem, é precisamente quem sabe bem deliberar) e parece constituir o cerne da racionalidade prática na medida em que institui um espaço de liberdade para o agente frente ao que está prestes a fazer. A noção aristotélica do que

corresponde à ordem adotada por Alexandre, ainda que não à ordem do De anima do próprio Aristóteles. 
Journal of Ancient Philosophy Vol. II 2008 Issue 2

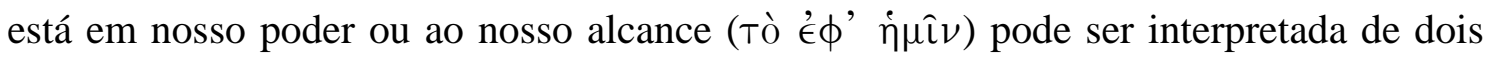
modos fundamentais:

(a) algo está no poder do agente quando o agente possui a capacidade de, neste caso particular, tanto fazer como deixar de fazer o que está prestes a realizar como meio adequado para obter um determinado fim;

(b) algo está no poder do agente quando o agente possui a capacidade geral de tanto fazer ou fazer o que está prestes a realizar, mas, neste caso particular, a sua natureza é tal que fará tal coisa ou não fará tal coisa como meio adequado para obter um determinado fim, não estando aberto a ele tanto fazer quanto não a fazer.

Pode-se discutir qual é precisamente a posição de Aristóteles; parece-me ser (a), mas isso não é tão importante aqui, porque Alexandre de qualquer modo atribui a Aristóteles a posição (a), que pode ser denominada de libertária: o agente está livre, em um sentido forte, para adotar ou deixar de adotar o meio adequado para obter um fim que já possui. Alexandre atribui (a) a Aristóteles em seu De fato, em um contexto em que está opondose claramente ao que ele caracteriza como o determinismo estóico. Contudo, o esquema que adota aqui não favorece (a), mas sim (b), pois retira do campo de deliberação este poder do sim e do não relativamente aos meios para se alcançar um objeto de desejo (тò o’ $€ \kappa$ Tó $\nu$ ); agora, ao contrário, uma vez dado o assentimento e então gerado o impulso, a razão tem procedimentos puramente instrumentais para a realização mais eficaz daquilo a que se deu o assentimento. Já no De fato Alexandre atribui (a) a Aristóteles não sem dificuldades, mas agora, analisando a faculdade motora à luz da faculdade impulsiva sob uma configuração tipicamente estóica, sua posição filosófica libertária fica em uma situação ainda mais delicada, exigindo alguma solução bem mais radical para poder assegurar a responsabilidade humana aos moldes de (a). ${ }^{6}$

Miguel de Éfeso, já mesmo por conta de seu elogio ao tratado Do impulso, o segue muito precisamente, não vendo nesta roupagem terminológica nenhum

\footnotetext{
${ }^{6}$ Um dos problemas que Alexandre enfrenta no De fato provém, porém, de sua interpretação da relação entre disposição e ação em uma chave psicológica determinista, que é uma questão da apropriação interna que faz do aristotelismo. Sobre isto, permito-me enviar ao meu artigo Ação, Caráter e Determinismo Psicológico em Alexandre de Afrodísia, Revista de Filosofia Antiga I 1 2007 (www.filosofiaantiga.com).
} 
Journal of Ancient Philosophy Vol. II 2008 Issue 2

problema, tampouco na ordem agora proposta para a análise da ação (a qual, no entanto, deveria corresponder à posição aristotélica). Em sua defesa, porém, deve-se dizer que ele transcreve partes importantes deste tratado no interior de seu comentário ao De motu animalium, cuja preocupação central consiste em fornecer uma explicação do movimento a todos os animais na perspectiva da junção entre a parte anímica e as articulações do corpo. Aristóteles, em seu De anima, assim alude ao estudo que se propõe a fazer nos tratados Parva Naturalia e no De motu: “quanto ao órgão pelo qual o desejo move < o animal>, isto é já algo corpóreo; por esta razão deve ser investigado nas funções comuns ao corpo e à alma” (De anima III 10 433b19-21). ${ }^{7}$ Ora, para este tipo de estudo, o problema do libertarismo ou do determinismo sai da frente da cena, deixando lugar a uma análise das conseqüências psicofisiológicas envolvidas na ação, nas quais as relações de determinação são as mais relevantes. Sinal disso é o fato que, no De motu, o exame dos silogismos práticos no capítulo 7 visa justamente a pôr em realce sua conclusão como que automática como ação (inclusive nos casos em que nem se pára para considerar a segunda premissa), ao passo que, na Ethica Nicomachea, sua presença no interior do tratado sobre a falta de controle visa a mostrar como é possível que um agente, embora disponha, em algum sentido, das premissas, no entanto não realiza a ação que é expressa na conclusão.

Outro ponto interessante é a divisão a que alude Alexandre da alma, em prática e crítica. Aristóteles não possui tal divisão. Alexandre toma a alma nutritiva como produtiva; a sensitiva é, de um lado, crítica; de outro, isto é, da perspectiva de sua função motora, ela é dita prática. Ao mesmo tempo, a alma racional é também crítica, o que provoca uma imbricação entre a sensitiva e a racional. Por outro lado, Alexandre propõe uma mesma instância: no caso da parte crítica, há uma que é diretiva (a racional) e uma outra, que é subordinada (a saber, a sensitiva e imaginativa). Isso o leva a propor igualmente uma mesma instância para a prática, dividida em duas partes: uma delas é diretiva - a saber, a propriamente impulsiva e desiderativa, e a outra é subordinada. A prática subordinada é a que está nos tendões e nervos, chamada de neurospastikon. Tudo isso está muito longe de Aristóteles, mas Miguel copia estas passagens sem

\footnotetext{
${ }^{7}$ Miguel, em seu comentário, toma o De motu como dando seguimento ao tratado Da memória $(103,13)$, em uma ordenação diferente da adotada por Bekker.
} 
Journal of Ancient Philosophy Vol. II 2008 Issue 2

pestanejar, alegando justamente que elas contêm a inteira concepção de Aristóteles a respeito da função motora nos animais.

O tema do silogismo prático nos permite passar ao último ponto, isto é, o quanto o tratado de Alexandre se refere ao De motu animalium. De fato, a menção é pequena. Após ter introduzido a faculdade impulsiva como causa, nos animais, do movimento local $(73,14-74,13)$, Alexandre volta a um tema que persegue de modo enfático em seu De anima, a saber, a distinção das faculdades e as relações que mantêm entre si $(74,13$ - 76, 16). Estes dois temas são gerais e pertencem propriamente a um tratado da alma; na parte final da segunda seção, Alexandre distingue entre a parte crítica e a impulsiva e, para cada parte, entre uma que comanda e outra que é subserviente; relativamente à parte impulsiva, a que comanda é dita impulsiva ou desiderativa, enquanto a subserviente é a que se encontra nos nervos e tendões (denominada, se o texto puder ser completado pelo relato de Miguel, neurospastikon). Na seção seguinte $(76,16$ - 78, 2), Alexandre passa a examinar então as contrações e relaxamentos que ocorrem, respectivamente, por resfriamento e aquecimento, o que corresponde principalmente ao tema da parte final do capítulo 7, mas também ao dos capítulos 8 e 10 do De motu (o exemplo da pequena alteração no leme que provoca grande mudança de rumo, dado em De motu 7 701b26-28, é retomado em 77, 9 - 10; o pneuma é mencionado duas vezes, em 77, 6 e 11, correspondendo ao seu tratamento em De motu 10). Na seção seguinte (78, 2 - 23), Alexandre volta a discutir as diferenças entre as partes da alma de um ponto de vista geral. Na seção final $(78,23$ - 80, 15), Alexandre retoma o ponto a respeito da alma que move sem que ela própria se mova. Aqui, ele distingue entre três tipos de movimento: o do motor imóvel em relação aos movimentos celestes, o da alma em relação ao animal e o que ocorre entre os seres inanimados. Este tema corresponde ao que é tratado no capítulo 6 do De motu; Alexandre termina o seu tratado mencionando dois silogismos práticos, aos quais se segue imediatamente a ação, que figuram no início do capítulo 7 do De motu (o do homem que deve passear, 7 701a13-14, e do manto a fazer, 7 701a17-20).

O De anima, bem como o intitulado Mantissa de Alexandre foram editados por Ivo Bruns (Praeter Commentaria Scripta Minora, Berlim 1887, CAG 
Journal of Ancient Philosophy Vol. II 2008 Issue 2

Supplementum Aristotelicum vol. II parte 1). Ivro Bruns cita extensamente a tradução que M. Steinschneider fez para o alemão da versão hebraica de Samuel ben Jehuda baseada em um texto árabe. Do De anima consultei a excelente edição italiana feita por P. Accattino e P. Donini (Laterza 1996); para Mantissa, consultei a edição de P. Accattino (Edizioni dell'Orso 2005) e a de R. Sharples (Ithaca 2004). O comentário ao De motu animalium de Miguel de Éfeso foi editado por Michael Hayduck no volume XXII / 2 dos Commentaria in Aristotelem Graeca (Berlim 1904); há uma tradução para o inglês em A. Preus, Aristotle and Michael of Ephesus - On the Movement and Progression of Animals (Olms 1981). A bibliografia de Alexandre está referida em R. Sharples, Alexander of Aphrodisias: scholasticism and innovation (Aufstieg und Niedergang der Römischen Welt II 36.II, pp. 1177 - 1243.

(I) Alexandre de Afrodísia De anima 73, 14 - 80, 15 (Peri tês hormêtikês dunameôs)

Foram ditas quais são as faculdades críticas da alma não-racional: são elas a faculdade sensitiva e a imaginativa, pois a faculdade lógica e dianoética, sendo 73,15 ela também crítica, é própria ao homem. Por isso, falaremos mais adiante a seu respeito $^{8}$; dá seqüência ao que foi dito precedentemente falar da faculdade impulsiva. ${ }^{9}$ Ela é, pois, princípio e causa da ação e do movimento local para os animais - para aqueles dentre estes que se movem deste modo - e seu lugar é após a faculdade imaginativa. Com efeito, o impulso parece seguir após o assentimento às imagens, como sendo o fim dele, não sendo mais crítico, mas pertencendo à outra parte da alma, a parte prática. Com efeito, a alma dos animais se divide em crítica e prática, a parte assim crítica e cognitiva tendo como referência a ação como a um fim, e cada uma é princípio da outra: a sensitiva é princípio da prática a título de princípio de onde surge o movimento, a prática é princípio da sensitiva a título de em vista de que e fim. A parte

\footnotetext{
${ }^{8}$ Alexandre examina a faculdade noética em 80, 16 - 92, 11.

${ }^{9}$ Adoto a pontuação proposta por Accattino-Donini, contra a do editor Bruns; o $\mu \epsilon ́ v$ de 73, 14 fica sem respondente.
} 
impulsiva conjuga-se com a desiderativa, pois esta é a faculdade que é para os animais princípio e causa do movimento local por eles próprios. Com efeito, <os animais> têm impulso e se movem ${ }^{10}$ ou, quando desejam algo, para o pegar, ou, se afastando, para recusar e fugir. O desejo, justamente, é um tipo de impulso. Um tipo de desejo é o 74,1 apetite; outro, a ira e outro, o querer. O desejo dos objetos agradáveis é apetite, o qual ocorre em todos os que participam da sensação; o desejo de vingar-se de alguém por ter feito pouco caso é denominado ira: tal desejo não ocorre mais em todos os que têm sensação. Com efeito, não ocorre em vermes nem em bivalves, mas nos que já são mais desenvolvidos. O desejo dos bens acompanhado de um juízo ${ }^{11}$ e deliberação é denominado querer, o qual ocorre unicamente nos homens. Com efeito, o querer é um desejo racional, mas racional não como sendo atividade da alma racional, mas como vindo como conseqüência das atividades daquela alma. Com efeito, a parte apetitiva, pelo fato de poder subordinar-se e obedecer à razão, quando deseja os objetos julgados pela razão, tal desejo da parte apetitiva é denominado querer, pois o querer é 74,10 acompanhado de deliberação ${ }^{12}$ e a deliberação e o deliberar pertencem à parte que tem razão.

Pode-se reconhecer pelos argumentos seguintes que a faculdade impulsiva é uma faculdade distinta da alma, mas também que as faculdades mencionadas anteriormente não somente se distinguem da impulsiva, mas também entre

10 73, 29 têm impulso e se movem: na edição Aldina, o texto seria "são impulsionados e movidos".

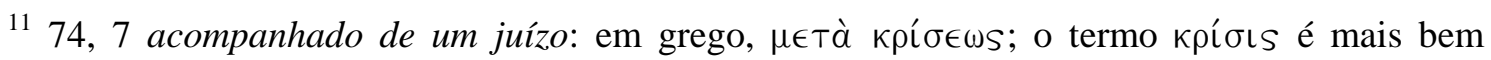
traduzido, em Alexandre, por "juízo", pois a discriminação, quando ocorre no homem, é feita sob forma judicativa. De fato, Alexandre vai propor uma importante reformulação da doutrina

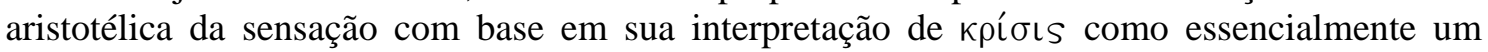
juízo (no homem); ela lhe servirá, por exemplo, para dar uma solução inovadora ao problema da percepção simultânea de contrários pela mesma faculdade sensitiva. O termo já havia figurado em "faculdade crítica".

12 74, 12 pois o querer é acompanhado de deliberação. Ao tomar o querer como seguido de deliberação, Alexandre altera consideravelmente a posição aristotélica; com efeito, para Aristóteles, o querer é um dos (três) tipos de desejo (portanto, figurando na parte não-racional da alma, mas capaz de escutar à razão) e ele pode (assim como também podem os outros dois tipos) ser objeto de deliberação, mas não é necessariamente acompanhado de deliberação (pois, como argumenta Aristóteles, posso querer ser imortal, mas não faz sentido ter deliberado ser imortal). 
si. A parte sensitiva se delimita da vegetativa por a primeira atribuir-se às plantas ${ }^{13}$, mas a segunda não. Com efeito, se fossem a mesma faculdade, onde estaria uma, estaria também a outra. Porém, quanto aos animais, a parte nutritiva está presente neles a partir da primeira formação (com efeito, o animal se alimenta apenas gerado e vive, quando está no ventre, em atividade somente por esta faculdade), ao passo que a alma sensitiva se engendra neles posteriormente, quando paridos. Com efeito, as contrações e os relaxamentos de certas partes que o animal produz quando no ventre, não se geram para ele em virtude de uma sensação própria, mas ele é movido por elas como parte de um ser animado. Ademais, sempre estamos em atividade pela faculdade nutritiva (pois sempre nos alimentamos e, ao que parece, sobretudo quando dormimos se dá a atividade desta faculdade), mas nem sempre estamos em atividade pela faculdade sensitiva. $O$ sono, pelo menos, consiste na inoperância e repouso das sensações; por isso a inatividade das sensações é o sono; a inatividade da faculdade nutritiva, a morte. E a parte nutritiva é produtiva, ao passo que a parte sensitiva é crítica e cognitiva. Ademais, todas as partes dos animais participam da parte nutritiva, se é verdade que todas elas se 75,1 alimentam, mas nem todas da sensitiva, se é verdade que cabelos, ossos e unhas são insensíveis.

Estas faculdades se distinguem umas das outras não somente pela definição, mas podem já ser distinguidas tanto pelo substrato quanto pela atividade. Segundo a definição, a diferença delas está no fato que não é a mesma a essência da parte nutritiva e a essência da parte sensitiva ${ }^{14}$ (pois é distinta a definição de cada parte 75,5 relativamente ao que é cada uma); segundo a atividade, diferem porque, quando está em atividade a parte nutritiva, nem sempre também está em atividade a parte sensitiva (pois a primeira está sempre em atividade, ao passo que a parte sensitiva dos que estão dormindo é inativa); segundo o substrato, porque a parte nutritiva se encontra em toda parte, mas a parte sensitiva não. E, nas plantas, encontra-se a parte nutritiva, mas não a parte sensitiva.

\footnotetext{
${ }^{13} 7416$ às plantas. É o texto (фuтô̂s) corrigido por Bruns (assim como na versão hebraica); os

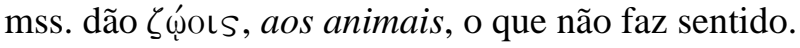

${ }^{14}$ 75, 5 a essência da parte nutritiva e a essência da parte sensitiva. Na linguagem tipicamente

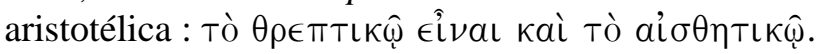


A parte impulsiva e desiderativa se distinguirá da parte nutritiva praticamente pelos mesmos aspectos pelos quais a parte sensitiva também se distingue da nutritiva. Ela diferirá somente em que a parte sensitiva se distingue da parte nutritiva por esta ser crítica, ao passo que aquela é produtiva; ora, a parte impulsiva não é crítica, como o é a sensitiva; ela é produtiva e prática, se é bem ela causa do movimento animal. 75,15 A parte impulsiva se distingue da sensitiva pela ordem temporal das atividades, pois as atividades de sensação e a imaginação que segue a sensação são primeiras relativamente às do desejo, pois estas últimas vêm como conseqüência e depois daquelas. Com efeito, o desejo é o fim de algumas atividades dos sentidos e, em todos os casos, a sensação ocorre antes do desejo, ao passo que não é em todos os casos que o desejo ocorre após a sensação. Se é isso, não é o caso que, quando ocorre uma delas, em todos os casos ocorre também a outra. Ademais, como já foi dito anteriormente, a sensação é causa para os animais de conhecimento e discriminação ${ }^{15}$, ao passo que o impulso e desejo são causa de ação. E a sensação reside no padecer, ao passo que o impulso e desejo são antes ativos e produtivos.

As faculdades da alma estão em relação umas com as outras (nos seres em que elas todas se encontram) de modo que as primeiras são com vista às últimas e 75,25 convergem de certo modo a estas, comportando-se analogamente às partes do corpo animado. Com efeito, assim como neste último uma parte se engendra e é com vista a outra (mas também a maioria das partes do corpo são com vista às atividades ${ }^{16}$ da alma, se é bem que o corpo animado é orgânico e que todo órgão é com vista àquilo a que serve), assim também, a propósito da alma, as primeiras partes são com vista às 75,30 segundas. Com efeito, a alma vegetativa é, nos animais, com vista à preservação e à existência, sem as quais tampouco existiria a parte sensitiva. A parte sensitiva e assim crítica é com vista à parte prática e impulsiva, como foi dito antes, mas também a parte prática e impulsiva é, por sua vez, com vista à parte crítica. Não, porém, da parte crítica sensitiva, mas do intelecto e da atividade deste, nos animais nos quais esta faculdade ocorre, como se mostra no tratado sobre eles.

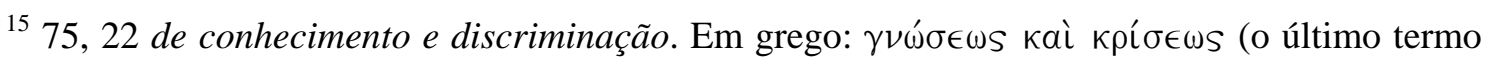
foi também traduzido por “juízo”).

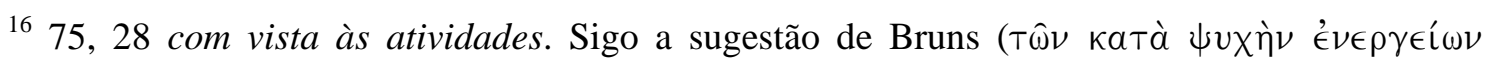

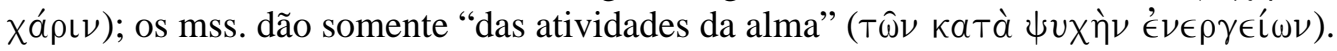


Foi dito então que as faculdades da parte impulsiva e desiderativa são várias e que diferem umas das outras quanto ao tempo, quanto aos objetos e quanto aos sujeitos a que pertencem. Havia sido dito antes que também há diferença entre as faculdades cognitivas e críticas. Com efeito, há uma faculdade subordinada crítica (esta é a faculdade sensitiva e imaginativa) e a parte diretiva ${ }^{17}$ da alma que é crítica (esta é a parte racional), a qual é reflexiva e noética. A parte sensitiva está referida à reflexiva, nos animais que possuem ambas, de modo a anunciar e indicar as diferenças dos objetos sensíveis a ele ${ }^{18}$. Assim como na parte crítica uma é diretiva e a outra é subordinada, assim também, na parte prática, uma é diretiva, a qual denominamos de impulsiva e desiderativa, a outra é algo que está nos tendões/nervos ${ }^{19}$. Há, pois, também neles uma faculdade, com base na qual o corpo subordina-se às atividades com base em um impulso. Dado que as coisas realizadas com base em um desejo são realizadas tendo ocorrido uma afecção, afecções ${ }^{20}$ que relaxam umas o corpo e provocam nelas ${ }^{21}$ um crescimento por meio de aquecimento equilibrado, ao passo que outras resfriam e contraem (pois as imaginações, as sensações e os pensamentos das coisas, gerando-se por uma semelhança a elas, como se aquelas estivessem presentes, relaxam o corpo ou o fazem contrair-se e tremer), contrações e expansões que, ocorrendo no pneuma congênito e se transmitindo deste aos tendões/nervos, estes podem ser movidos nas atividades com base em um impulso, recebendo o princípio do movimento do desejo, pois uma pequena mudança ocorrida no princípio se torna causa de muitas e grandes diferenças: o leme sendo deslocado imperceptivelmente, grande se torna o

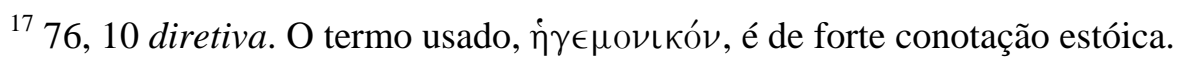

${ }^{18} 76,13-14$ as diferenças dos objetos sensíveis a ele. O texto em grego pode tanto dizer que a parte sensitiva comunica à reflexiva as diferenças que lhe (à sensação) são dadas como também que a parte sensitiva comunica a ela (à parte reflexiva) as diferenças dos objetos sensíveis.

${ }^{19}$ 76, 16 nos tendões/nervos. Em grego: év Tô̂s veúpoıs. O termo $v \in u ́ p o \nu$ em Aristóteles designa tudo o que faz mover corporalmente aos moldes de uma corda, o que inclui tendões, músculos e nervos. Os nervos foram distinguidos dos músculos logo após a morte de Aristóteles, mas os comentadores nem sempre levavam em conta estas inovações (como estão presentes, por exemplo, em Galeno).

${ }^{20}$ 77, 1 afecções que. Este é o primeiro de uma série de anacolutos, o que é raro em Alexandre (Miguel os copiará verbatim). O texto daria, literalmente: cujas afecções umas relaxam ktl.

${ }^{21} 77,1$ nelas. Isto é: nas partes. Bruns sugeriu o singular, o que resultaria que o crescimento se daria no corpo. No entanto, o plural está também em Miguel 115,9, e deve ser entendido como

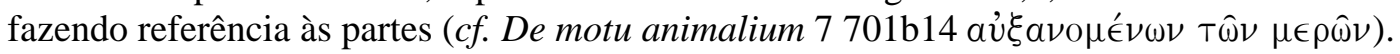


deslocamento da proa; já no entorno do coração e o pneuma nele, quando ocorre uma alteração pelas sensações ou pensamentos de certas coisas, às quais se seguem um movimento e afecção, se uma tal mudança se produz nele, ainda que em uma parte imperceptível, pelo fato do coração ser o princípio do animal produz muita modificação de todo o corpo por rubores, palores, calores, frios, arrepios e tremores.

O que é objeto de busca e de fuga no campo da ação é princípio, então, do movimento; impulso é, pois, movimento do ser animado que se gera com base em uma imaginação de algo a ser buscado ou evitado. Calor e frio necessariamente acompanham o pensamento e a imaginação deles, pois praticamente todos os estados dolorosos e prazerosos são seguidos de um frio e calor. Quando ocorrem em nós, vemos por vezes algumas partes que se movem em nós, como nas poluções noturnas, por vezes também o corpo inteiro. As quais afecções, quando se geram nos princípios das partes orgânicas relativos às atividades, conduzem elas próprias os serviços à faculdade impulsiva, de onde também têm o princípio. Todas as ações deste tipo se realizam pela 78,1 atividade das partes do corpo.

Ficou esclarecido pelo que foi dito quais partes dos animais pertencem à alma comum e quais são suas diferenças umas com as outras ${ }^{22}$. Estas são as atividades próprias de cada uma delas: o viver é a atividade da parte nutritiva, sendo comum ao animal e à planta. Vida é, como dito ${ }^{23}$, o alimentar-se e crescer por si próprio. O ter sensação, o qual é próprio do animal, estando após o viver, é atividade da alma sensitiva, que ocorre graças à apreensão das formas sensíveis sem matéria por meio dos órgãos sensitivos; desta atividade, o ver pertence à visão; o escuta, à audição, e os outros similarmente, ao passo que o próprio ter sensação pertence à sensação comum. E, 78,10 como no caso da sensação, julgamos os sensíveis particulares por meio dos órgãos sensitivos particulares, mas os sensíveis em conjunto pela sensação comum, como toda sensação ocorrendo pela mesma instância, contudo cada sensação segundo cada órgão, assim, por sua vez, dado que a sensação é uma certa discriminação ${ }^{24}$ e que há outras

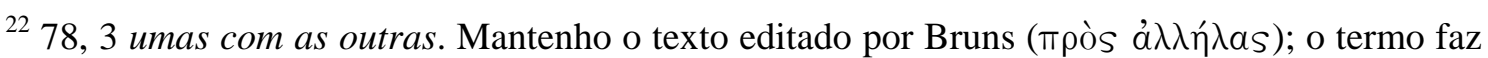

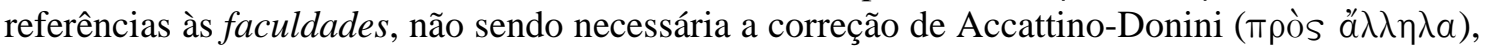
referindo o termo às partes.

${ }^{23} 78,5$ como dito. Em De anima 29, 10.

${ }^{24}$ 78, 13 discriminação. Aqui, como nas linhas seguintes, o termo grego é sempre крíøıs.
} 
discriminações, como o imaginar, o assentir, o apreender, o conceber, o opinar, o 78,15 conhecer, o calcular, o refletir, o pensar, temos de conceber todas as discriminações se gerando de uma mesma e comum instância (a saber, a crítica), mas cada discriminação ocorrendo pela mesma instância segundo uma ou outra faculdade, como fora o caso para a sensação. Com efeito, pertencem à parte crítica o imaginar, o assentir, o apreender, o 78,20 conceber, o opinar e o compreender, cujas diferenças discriminamos pela parte crítica comum.

Assim como há uma parte crítica comum, assim, por sua vez, também há uma parte impulsiva e desiderativa comum. Com efeito, o desejo é um impulso a algo, do qual um é o apetite, o outro é a ira, o terceiro é o querer. A alma impulsiva e desiderativa move o animal não se movendo ela própria, como foi dito anteriormente ${ }^{25}$, 78,25 pois toda enteléquia é imóvel por si e foi demonstrado que a alma é enteléquia. Por isso tampouco se diz apropriadamente que o corpo é movido pela alma. Com efeito, diz-se isso quando o que move e o que é movido estão separados, como os bois que movem o carro, mas, dado que se diz também, em sentido lato, que é movido por algo o que se move em virtude desse algo (assim se diz que o artesão é movido pela arte porque se 79,1 move em virtude dela, e assim também que o fogo se move pela leveza ${ }^{26}$ ), assim também se diz que o animal é movido pela alma porque se move em virtude dela. Com efeito, um tal movimento lhe toca por ser animado, não por ser pesado, leve, branco, escuro, quente ou frio.

Nem tudo que é dito mover move de mesmo modo. Uns movem como dizemos que o objeto de desejo e de atração move; com efeito, todo objeto de amor move o amante por atração a ele, sendo externo, sem que ele seja movido de si. Por isso nenhum ser inanimado é movido pelo que é capaz de mover deste modo. A alma move o animal pelo fato deste se mover em virtude do desejo e do impulso que está nele graças à alma por algo que percebeu ou pensou com vista à busca ou à fuga. Os seres inanimados movem chocando-se a estes que movem, isto é, por violência, estando

\footnotetext{
${ }^{25}$ 78, 25 como foi dito anteriormente. Na verdade, não foi dito em nenhum lugar anteriormente, mas, em geral, na primeira parte do De anima, este foi um dos temas principais para toda a alma.

${ }^{26}$ 79, 2 pela leveza. Na versão de Miguel, há ainda: pela leveza em virtude dela, o que segue mais de perto a analogia proposta.
} 
Journal of Ancient Philosophy Vol. II 2008 Issue 2

separados deles. Um tal movimento, então, se dá por motores que são eles próprios movidos, mas os movimentos descritos antes deste ${ }^{27}$ não ocorrem deste modo. Com efeito, nem o que move por ser pensado move sendo movido nem o que se move por pensar algo e o desejar e ter impulso a isso é movido pelo fato de o que pensa ser movido assim por isso. O animal sente, pensa e caminha em virtude da alma, a própria alma, porém, não se movendo por si mesma para que mova. Com efeito, não é porque o dançarino se move em virtude da arte da dança que por isso também a arte da dança deva necessariamente se mover por si mesma. Com efeito, a alma não está em nós como o remador está no barco, mas como certa forma e perfeição, como foi demonstrado. Porém, a respeito disto falamos também no início. ${ }^{28}$

Não se deve considerar o pensamento ou a imaginação, porque precedem o movimento, serem eles por isso os motores, mas, porque sem impulso e desejo nenhum daqueles dois move, deve-se atribuir o movimento a estes últimos. Com efeito, dado que o desejo ocorre quando precedido por um daqueles, não é já um daqueles o motor; ao contrário, porque não são de nenhuma utilidade quanto ao movimento, se não há um impulso e não sobrevém um desejo, deve-se considerar que é este último que é quem move. Com efeito, se o animal há de ser movido, é preciso que ele primeiro como que afirme ou negue, pois é um tal estado do animado concernente às ações que é causa do movimento local. E, a propósito das ações racionais - entendo por racionais as ações praticadas pelos seres racionais com base em uma razão, e estas são as que a razão comanda, as quais se poderia chamar propriamente de ações ${ }^{29}$ ), destas por certo o impulso e o desejo são causa. Com efeito, não há nada de útil em deliberar sobre o que se deve fazer, se a escolha deliberada não vai se seguir, a qual é um desejo deliberativo. Com efeito, assim, como, nos itens teóricos, a conclusão demonstrada com base no que foi assumido é o conhecimento do objeto em questão, assim, nos itens de ação, a ação se

\footnotetext{
${ }^{27}$ 79, 13 antes deste. Sigo o texto proposto por Bruns; o principal manuscrito (V) dá antes destes e a edição Aldina em relação a estes. Há três tipos de movimento: (i) o causado pelo Primeiro Motor, que move como causa final, sem ser movido; (ii) o dos animais e (iii) o dos seres inanimados.

${ }^{28}$ 79, 21 falamos também no início. Alexandre remete à primeira parte de seu De anima (pp. 126).

${ }^{29}$ 80, 4-5 as quais se poderia chamar propriamente de ações. Esta tese é defendida, em particular, na Ethica Eudemia II 6 1222b19-20 e, mais fortemente, II 8 1224a28-30.
} 
Journal of Ancient Philosophy Vol. II 2008 Issue 2

torna a conclusão do querer ${ }^{30}$. Demonstrou-se, pois, que, ao mesmo tempo, é preciso 80,10 perseguir algo ou fugir e, se o desejo se põe a caminho do que foi mostrado, e que isto ocorre, a menos que haja algo que impeça do exterior. Com efeito, quem pensa: todo homem deve caminhar, eu sou um homem, tira como conclusão das premissas mencionadas precedentemente o caminhar. E também quem pensa: preciso de uma roupa, o manto é uma roupa, leva a conclusão “preciso, portanto, de um manto” para o fabricar de um manto.

(II) Miguel de Éfeso In librum De animalium motione commentarium 114, 22 - 116, 14

De quais órgãos a alma se serve para mover o animal e, em geral, como ela move o animal sem ser movida, foi explicado quando do tratado do impulso e da faculdade impulsiva. Por isso quem quiser obter a verdade deve ler a inteira concepção de Aristóteles deste livro; agora, contudo, vamos transcrever um pouco do que está escrito lá. É dito primeiramente que as faculdades da parte desiderativa e impulsiva são várias e, por último, que também há diferença entre as faculdades cognitivas e críticas. Com efeito, uma é certa faculdade subordinada crítica (esta é a faculdade sensitiva e a imaginativa), a outra é uma parte diretiva da alma que é crítica; esta é a parte racional, a qual é reflexiva e noética. A parte sensitiva está referida à reflexiva, nos animais que possuem ambas, de modo a anunciar e indicar as diferenças dos objetos sensíveis a ele. Assim como na parte crítica uma é diretiva e a outra é subordinada, assim também, na parte prática, uma é diretiva, a qual denominamos de impulsiva e desiderativa, a outra é algo que está nos tendões/nervos a título de subordinada, que denominamos também de “neurospastikon”. Há, pois, também neles uma faculdade, com base na qual o corpo subordina-se às atividades com base em um impulso. Dado que as coisas realizadas por desejo são realizadas tendo ocorrido uma afecção, afecções que relaxam umas o corpo e provocam nelas um crescimento por meio de aquecimento equilibrado, ao passo que

\footnotetext{
${ }^{30}$ 80, 9-10 conclusão do querer. A versão hebraica, na tradução de Steinschneider, dá como texto Folgerung des Ratschlages, o que supõe como texto conclusão da deliberação e não do querer (em grego: $\beta o u \lambda \epsilon \hat{\sigma} \sigma \epsilon \omega$ s e não $\beta o v \lambda \eta ́ \sigma \epsilon \omega s)$. No entanto, o querer implica, para Alexandre, a deliberação (ver 74,12, nota 13).
} 
outras resfriam e contraem (pois as imaginações, as sensações e os pensamentos das

coisas, gerando-se por uma semelhança a elas, como se aquelas estivessem presentes, relaxam o corpo ou o fazem contrair-se e tremer), contrações e expansões que, ocorrendo no pneuma congênito e se transmitindo deste aos tendões/nervos, estes podem ser movidos nas atividades com base em um impulso, recebendo o princípio do movimento do desejo, pois uma pequena mudança ocorrida no princípio se torna causa de muitas e grandes diferenças: o leme sendo deslocado imperceptivelmente, grande se torna o deslocamento da proa; já no entorno do coração e o pneuma nele, quando ocorre uma alteração pelas sensações ou pensamentos de certas coisas, às quais se seguem um movimento e afecção, se uma tal mudança se produz nele, ainda que em uma parte 115,20 imperceptível, pelo fato do coração ser o princípio do animal produz muita modificação de todo o corpo por rubores, palores, calores, frios, arrepios e tremores.

O que é objeto de busca e de fuga no campo da ação é princípio, então, do movimento; impulso é, pois, movimento do ser animado que se gera com base em uma imaginação de algo a ser buscado ou evitado. A alma impulsiva e desiderativa 115,25 move o animal não sendo ela própria movida, como foi dito anteriormente, pois toda enteléquia é imóvel por si e foi demonstrado que a alma é enteléquia. Por isso tampouco se diz apropriadamente que o corpo é movido pela alma (com efeito, diz-se isso quando o que move e o que é movido estão separados, como os bois que movem o carro), mas, dado que se diz também, em sentido lato, que é movido por algo o que se move em 115,30 virtude desse algo (assim se diz que o artesão é movido pela arte porque se move em virtude dela, e assim também que o fogo se move pela leveza porque se move em virtude dela ${ }^{31}$ ), assim também se diz que o animal é movido pela alma porque se move em virtude dela; com efeito, um tal movimento lhe toca por ser animado, não por ser pesado, leve, branco, escuro, quente ou frio. O animal sente, pensa e caminha em virtude da alma, a própria alma, porém, não se movendo por si mesma para que mova. Com efeito, move como o dançarino se move em virtude da arte da dança e os artesãos em virtude das artes e são estas as causas de tal movimento para eles, estas que não se movem (pois nem as artes nem a arte da dança se movem), assim também os seres

31 115, 32 porque se move em virtude dela. Esta parte não ocorre no texto que nos foi transmitido de Alexandre. 
Journal of Ancient Philosophy Vol. II 2008 Issue 2

animados são movidos em virtude da alma, a alma não sendo movida. É a faculdade impulsiva e desiderativa da alma aquela em virtude da qual os animais se movem, pois ela é causa do movimento próprio para os animais. E a alma não está em nós como o remador está no barco, mas como certa forma e perfeição, como foi dito no tratado do 116,10 impulso e da faculdade impulsiva. Estas coisas admitidas são suficientes para apresentar com clareza os pontos que se pretende; quem quiser saber mais sobre estas coisas deve tomar o tratado do impulso. Vamos continuar em seqüência com as passagens de Aristóteles.

(III) Alexandre de Afrodísia De anima líber alter [Mantissa] 105, 26 - 106, 17

A faculdade nutritiva se divide em alimentar, crescer e se reproduzir; a sensitiva, em ter sensação, ter imaginação, lembrar e assentir; a parte impulsiva é como um fim da imaginação e do assentimento, pois aqueles são com vista a esta. Com efeito, sempre o assentimento precede o impulso e a imaginação precede o assentimento. Desta 105,30 parte impulsiva e prática, uma parte é como diretiva, a outra como subordinada; denominamos diretiva o que é propriamente impulsivo e desiderativo; a outra, denominamos neurospastikon, na qual se encontra também o que é fonador. Da parte impulsiva há o ter apetite, o irar-se e o querer, pois eles são espécies do desejo. Destes, 106,1 o querer parece já participar do raciocínio; com efeito, é um desejo acompanhado de deliberação. Há uma outra faculdade da alma crítica, a racional, a qual ocorre nos animais mais desenvolvidos. Este é o homem; pertencem a esta faculdade o deliberar, o compreender e o opinar. A alma move o corpo não como se movendo ela própria e 106,5 assim o movendo (pois ela é imóvel em si mesma), mas como causa do movimento para o animal, como o peso que inere à terra é causa do movimento para baixo. Com efeito, nem todos os que movem movem do mesmo modo. Com efeito, de um modo os bois movem o carro, de outro modo o bem objeto de tendência, isto é, o objeto de desejo move os que tendem a ele: move sem se mover. Por isso o movimento por coisas deste tipo também é o dos seres animados. A alma move pelo fato que, em virtude dela, nós pensamos e escolhemos por deliberação. O bem move por ser pensado, a alma por 
Journal of Ancient Philosophy Vol. II 2008 Issue 2

pensar. Assim como os artesãos se movem pelas artes e em virtude das artes e são estas as causas de tal movimento para eles, elas não se movendo, assim também os seres 106,15 animados se movem em virtude da alma, ela não se movendo. É a faculdade impulsiva e a desiderativa da alma aquela em virtude da qual os animais se movem. Ela é, com efeito, causa do movimento próprio para os animais.

Referências Bibliográficas

Accatino, P. De anima II (Mantissa). Edizioni dell'Orso 2005.

Accattino, P. e Donini, P. Alessandro di Afrodisia - L'anima. Laterza 1996.

Bruns, I. Alexandri Aphrodisiensis Praeter Commentaria Scripta Minora. Berlim 1887.

Donini, P. Il De anima di Alessandro di Afrodisia e Michele Efesio. Rivista de Filologia e de Istruzione Classica XCVI / 3 1968, pp. 316-323.

Hayduck, M. Michaelis Ephesii in libros de partibus animalium, de animalium motione, de animalium incessu commentaria. CAG XXII / 2 Berlim 1904.

Preus, A. Aristotle and Michael of Ephesus - On the Movement and Progression of Animals. Olms 1991.

Sharples, R.W. Alexander of Aphrodisias - Supplement to On the Soul. Ithaca 2004.

Sharples, R.W. Alexander of Aphrodisias: scholasticism and innovation. Aufstieg und Niedergang der Römischen Welt II 36.2 pp. 1176-1243. 